\title{
Simultaneous spectrophotometric determination of copper(II), lead(II) and cadmium(II)
}

\begin{abstract}
Shouxin Ren and Ling Gao
Department of Chemistry, Inner Mongolian University, 010021 Huhehot, Inner Mongolia, China

The full spectrum technique in the fourier domain was studied for simultaneous determination of $\mathrm{Cu}(I I), P b(I I)$ and $C d(I I)$ with 4-(2-pyridylazo) resorcinol (PAR). A program called SPGRFSQ was designed to perform the calculations. Seven error functions were calculated for deducing the number of factors. Data reduction was performed using principal component analysis (PCA) algorithm. Experimental results showed the method to be successful even where there was severe overlap of spectra.
\end{abstract}

\section{Introduction}

The development of chemometric methods of multicomponent analysis has allowed the resolution of the complex spectra of mixtures of analytes. Various research groups have reported using chemometric methods to resolve overlapping spectra [1, 2]. Multicomponent determinations have recently been improved by using the full spectrum method and different chemometric algorithms [3, 4].

Simultaneous determination of copper(II), lead(II) and cadmium(II) with 4-(2-pyridylazo) resorcinol (PAR) using traditional spectrophotometry is difficult because (1) the absorption spectra overlap; and (2) the superimposed curve is not suitable for quantitative evaluation. In a $P \Lambda R$ system, in addition to low selectivity, problems arise because of strong absorbance of the reagent. This paper shows that multicomponent analysis with full spectrum methods is a solution.

\section{Experimental}

\section{Instruments and apparatus}

The Shimadzu UV-265 and UV-120 spectrophotometers were used for all experiments; a GW286 EX/16 microcomputer with a maths coprocessor was used for the calculations; and a Mettler DL 21 titrator was used for standardization of the standard solutions.

\section{Reagents}

$\Lambda$ ll reagents were of analytical reagent grade. The water used was doubly distilled and deionized. Stock standard solutions of $\mathrm{Cu}(\mathrm{II}), \mathrm{Pb}(\mathrm{II})$ and $\mathrm{Cd}(\mathrm{II})$ were prepared from nitrates and standardized titrimetrically with EDT $\Lambda$. Buffer solution ( $\mathrm{pH} 7 \cdot 0$ ) was prepared from borax solution and hydrochloric acid solution; a $0.02 \% \mathrm{~m} / \mathrm{v}$ PAR solution in alcohol was used.

\section{Procedure}

A series of mixed standard solutions containing various ratios of the three metal ions at $\mathrm{pH} 7 \cdot 0$ was prepared in $50 \mathrm{ml}$ standard flasks, $1 \mathrm{ml} 0.02 \% \mathrm{~m} / \mathrm{v}$ PAR solution in alcohol, $15 \mathrm{ml}$ of buffer solution $(\mathrm{pH} \mathrm{7.0)}$ and dilution with distilled water to mark. Cuvettes with a path length of $1 \mathrm{~cm}$ were used and the blank absorbance due to PAR absorption was subtracted. Absorbances were measured between $460 \mathrm{~nm}$ and $560 \mathrm{~nm}$ at 5 and $2 \mathrm{~nm}$ distances, giving values at 33 wavelengths for each standard solution. An absorption matrix, $D$, was built up from these data.

\section{Computer program and algorithms}

The $D$ matrix, obtained as described above, is transformed using fast fourier transform (FFT) to produce the $F$ matrix. The variance-covariance matrix $A\left(\mathrm{FF}^{1}\right)$ can be subjected to singular value decomposition for calculation of the eigenvalues and eigenvectors. The number of species is estimated by several criteria, which are based on the theory of error in factor analysis [5-7]. After determining the number of species $(t)$, the set of $t+2$ significant eigenvectors becomes the basis eigenvectors $(\mathbf{U})$. The projection of each standard mixture is calculated by $M=\mathrm{U}^{\mathrm{T}} F$. A proportionality matrix, $P$, is found by least squares regression analysis, $P=C_{\mathrm{k}} M^{\mathrm{T}}\left(M M^{\mathrm{T}}\right)^{-1}$. The absorbance spectra for unknown mixtures is converted to the fourier domain and represented as $F u$. The projection matrix $(M u)$ is obtained by matrix multiplication: $M u=\mathbf{U}^{\mathrm{T}} F u$. The projection matrix $(M u)$ is then multiplied by $P$ to give the unknown concentration as $C u=P M u$. A program called SPGRFSQ, which is based on the algorithm, was designed to perform the calculation.

\section{Results and discussion}

\section{Determination of the number of factors}

Seven criteria were used to calculate the number of factors-see table 1. Results are shown in table 2. The minimum of the Frac function appeared at $t=4$ : the appropriate number of eigenvectors is one less than that giving the minimum frac value. Figure 1 shows the Frac function plotted against the number of factors; the number of factors was 3 . The magnitude of REV decreased rapidly until $t=3$, then it stabilized. The IND function reached a minimum at 2-4; the magnitude of the first four eigenvalues were larger than those of 5-8; and a maximum of the eigenvalue ratio (ER) function appeared at 4 . The discrepancy in these results was probably due to the existence of some other weakly absorbing species. The speciation of the system was very complex. The results 
Table 1. Factor analysis criteria.

\begin{tabular}{llll}
\hline \multicolumn{1}{c}{ Name } & \multicolumn{1}{c}{ Formulae } & Name & Formulae \\
\hline Rear crror & $\mathrm{RE}=\left[\frac{\sum_{j=n+1}^{k} \lambda_{j}}{L(k-n)}\right]^{1 / 2}$ & Indication function & $\mathrm{IND}=\mathrm{RE} /(k-n)^{2}$ \\
Extracted crror & $\mathrm{XE}=\mathrm{RE}\left(\frac{k-n}{k}\right)^{1 / 2}$ & Eigenvalue ratio & $\mathrm{ER}_{j}=\lambda_{j} / \lambda_{j+1}$ \\
Imbedded error & $\mathrm{IE}=\mathrm{RE}\left(\frac{n}{k}\right)^{1 / 2}$ & Reduced eigenvalue & $\mathrm{REV}_{j}=\frac{\lambda_{j}}{(L-j+1)(k-j+1)}$ \\
Fraction function & $\mathrm{FRAC}=\frac{\lambda_{j}}{\sum_{j=1}^{k} \lambda_{j}}$ & & \\
\hline
\end{tabular}

Table 2. Results on factor analysis for the $C u(I I) / P b(I I) / C d(I I) / P A R$ systems.

\begin{tabular}{|c|c|c|c|c|c|c|c|c|}
\hline$t$ & $\begin{array}{c}\mathrm{EV} \\
\times 1 \cdot 0 \mathrm{E}-3\end{array}$ & RE & IND & $\mathrm{XE}$ & IE & ER & REV & Frac \\
\hline 1 & $2 \cdot 0305$ & $0 \cdot 0926$ & $0 \cdot 0019$ & $0 \cdot 0866$ & $0 \cdot 0327$ & $556 \cdot 5122$ & $3 \cdot 9658$ & $0 \cdot 9981$ \\
\hline 2 & $0 \cdot 0036$ & $0 \cdot 0224$ & $0 \cdot 0006$ & $0 \cdot 0194$ & $0 \cdot 0112$ & $33 \cdot 7469$ & $3 \cdot 0083$ & $0 \cdot 0018$ \\
\hline 3 & $0 \cdot 0001$ & $0 \cdot 0162$ & $0 \cdot 0006$ & $0 \cdot 0128$ & $0 \cdot 0099$ & $1 \cdot 8777$ & $0 \cdot 0003$ & $0 \cdot 0001$ \\
\hline 4 & $0 \cdot 0001$ & $0 \cdot 0102$ & $0 \cdot 0006$ & $0 \cdot 0072$ & $0 \cdot 0072$ & $3 \cdot 6458$ & $0 \cdot 0002$ & $0 \cdot 0000$ \\
\hline 5 & $0 \cdot 0000$ & 0.0075 & $0 \cdot 0006$ & $0 \cdot 0046$ & $0 \cdot 0060$ & $1 \cdot 7198$ & $0 \cdot 0001$ & $0 \cdot 0000$ \\
\hline 6 & $0 \cdot 0000$ & $0 \cdot 0037$ & $0 \cdot 0008$ & $0 \cdot 0018$ & $0 \cdot 0032$ & $8 \cdot 5655$ & $0 \cdot 0001$ & $0 \cdot 0000$ \\
\hline 7 & $0 \cdot 0000$ & $0 \cdot 0032$ & $0 \cdot 0009$ & $0 \cdot 0011$ & $0 \cdot 0030$ & $1 \cdot 6268$ & $0 \cdot 0000$ & $0 \cdot 0000$ \\
\hline 8 & $0 \cdot 0000$ & - & $0 \cdot 0032$ & - & - & - & $0 \cdot 0000$ & $0 \cdot 0000$ \\
\hline
\end{tabular}

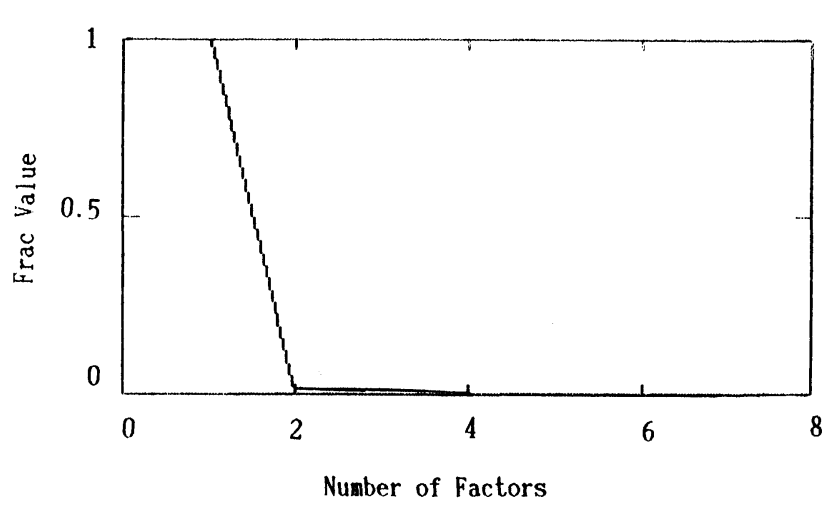

Figure 1. Plot of the Frac function against factor number.

indicated that three absorbing components may be present.

\section{The training set model}

Figure 2 shows the absorption spectra of $\mathrm{Cu}(\mathrm{II}), \mathrm{Pb}(\mathrm{II})$, $\mathrm{Cd}(\mathrm{II})$ and their mixed solution with PAR as reagent. The absorption maximums of $\mathrm{Cu}(\mathrm{II}), \mathrm{Cd}(\mathrm{II})$ and $\mathrm{Pb}(\mathrm{II})$ complexes were $507 \mathrm{~nm}, 498 \mathrm{~nm}$ and $512 \mathrm{~nm}$, respectively. The concentrations of the three metal ions in eight standard solutions are shown in table 3 . The spectra were measured between $460 \mathrm{~nm}$ and $560 \mathrm{~nm}$ at 5 and $2 \mathrm{~nm}$ distances, giving values at 33 wavelengths for every standard solution. Each of the spectra of the training set were corrected by subtracting the standard spectrum of reagent, then an absorption matrix, $D$, was built up.

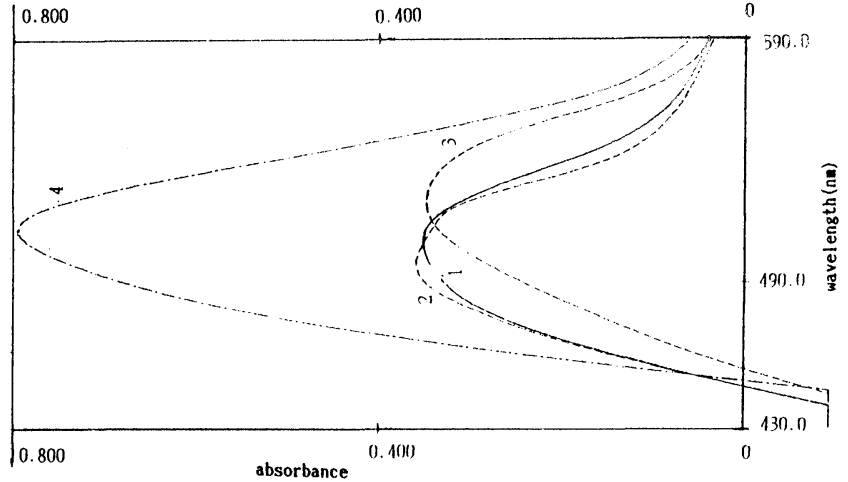

Figure 2. Absorption spectra of $C u(I I), P b(I I), C d(I I)$ and their mixed solution with $P A R$ as reagent. $1: 1.2 \times 10^{-5} \mathrm{~mol} / \mathrm{l} \mathrm{Cu}(\mathrm{II})$. 2: $1.2 \times 10^{-5} \mathrm{~mol} / \mathrm{l} \mathrm{Pb}(\mathrm{II})$. 3: $1.2 \times 10^{-5} \mathrm{~mol} / \mathrm{l} \mathrm{Cd}(\mathrm{II})$. 4: $1.2 \times 10^{-5} \mathrm{~mol} / \mathrm{l} \mathrm{Cu}(\mathrm{II})+1.2 \times 10^{-5} \mathrm{~mol} / \mathrm{l} \mathrm{Pb}(\mathrm{II})+1.6 \times$ $10^{-5} \mathrm{~mol} / \mathrm{l} \mathrm{Cd}(\mathrm{II})$.

Figure 3 is a three-dimensional plot of spectra of the training set obtained at 33 different wavelengths. Matrix $D$ was transformed with the use of a standard FFT principal. The fourier transform method also acts as a filter, since the high frequency noise terms can be deleted producing a significant reduction of error. The $F$ matrix preserved the important property of the Lambert-Beer relationship. The $P$ matrix is the calibration matrix and provides all the information that is needed to calculate the concentration of the unknown samples from the $F u$ 
Table 3. Composition of the standard solutions.

\begin{tabular}{cccc}
\hline & \multicolumn{3}{c}{ Concentration $(\mathrm{mmol} / \mathrm{l})$} \\
\cline { 2 - 4 } $\begin{array}{c}\text { Solution } \\
\text { number }\end{array}$ & $\mathrm{Cu}(\mathrm{II})$ & $\mathrm{Pb}(\mathrm{II})$ & $\mathrm{Cd}(\mathrm{II})$ \\
\hline 1 & $0 \cdot 0165$ & 0.9968 & 0.5869 \\
2 & $0 \cdot 8739$ & $1 \cdot 0134$ & 0.6319 \\
3 & $0 \cdot 6427$ & $0 \cdot 8944$ & $1 \cdot 0318$ \\
4 & 1.0143 & $1 \cdot 3534$ & 0.9335 \\
5 & $0 \cdot 5233$ & $0 \cdot 7828$ & 0.9203 \\
6 & $0 \cdot 4923$ & 0.6448 & 0.5277 \\
7 & $1 \cdot 0975$ & $1 \cdot 0985$ & 0.7155 \\
8 & $0 \cdot 7770$ & 0.9470 & 0.9489 \\
\hline
\end{tabular}

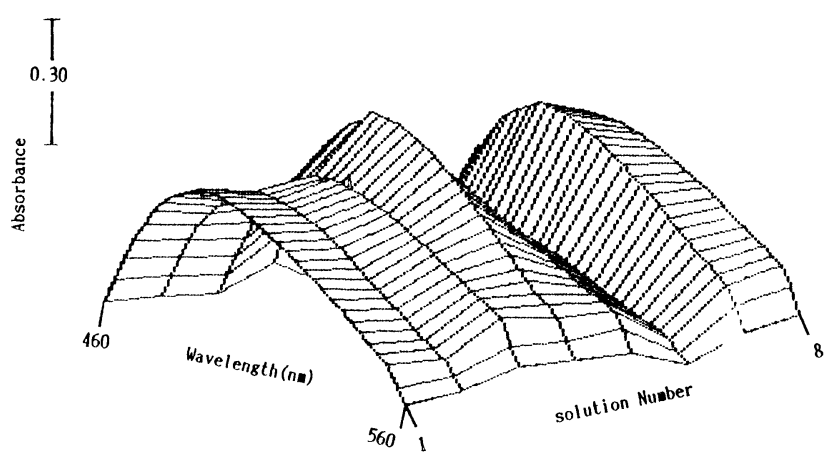

Figure 3. Three-dimensional plot of the spectra in the training set.

Table 4. P matrix of the training set with five basis eigenvectors.

\begin{tabular}{rrrrr}
\hline 0.0156 & 0.1863 & 0.5264 & -0.1575 & -0.0272 \\
0.0617 & 0.1065 & -0.3737 & -0.1638 & 0.0490 \\
0.0497 & -0.2176 & -0.5462 & 0.2219 & 0.0217 \\
\hline
\end{tabular}

matrix. The $P$ matrix was calculated using SPGRFSQ as shown in table 4.

\section{Data reduction}

Data reduction was based on the PCA algorithm. Using the SPGRFSQ program, the concentrations of 'unknowns' and the $P$ matrix were calculated while varying the number of basis eigenvectors. The results are given in table 5. Based on the results, it is recommended that five eigenvectors are used for analysis; eigenvectors above 6 should be ignored.

\section{Determination of unknowns}

The added concentrations of a set of eight synthetic 'unknown' samples are shown in table 6. The spectra of the unknown samples were measured in the same way as the training set model. Using SPGRFSQ the concentrations of the $\mathrm{Cu}(\mathrm{II}), \mathrm{Pb}(\mathrm{II})$ and $\mathrm{Cd}(\mathrm{II})$ were found and are given in table 7 . Average recoveries and their relative deviations are listed in table 8 . The experimental results showed that the full spectrum techniques in the fourier domain gave satisfactory results for simultaneous determination of a complex mixture with severely overlapping spectra.

Table 5. Relationship between numbers of eigenvector and relative deviation of 'unknowns' determination.

\begin{tabular}{clrrr}
\hline \multirow{2}{*}{$\begin{array}{c}\text { Numbers } \\
\text { of } \\
\text { eigenvector }\end{array}$} & & \multicolumn{3}{c}{ Relative deviation (\%) } \\
\cline { 3 - 5 } & & \multicolumn{3}{c}{ 'Unknowns' number } \\
\cline { 2 - 5 } 3 & $\mathrm{Cu}(\mathrm{II})$ & $-0 \cdot 0061$ & $-0 \cdot 0172$ & $-0 \cdot 0302$ \\
& $\mathrm{~Pb}(\mathrm{II})$ & $-0 \cdot 0031$ & $-0 \cdot 0166$ & $-0 \cdot 0313$ \\
& $\mathrm{Cd}(\mathrm{II})$ & $0 \cdot 0068$ & $0 \cdot 0706$ & $0 \cdot 0273$ \\
4 & $\mathrm{Cu}(\mathrm{II})$ & $-0 \cdot 0021$ & $-0 \cdot 0022$ & $0 \cdot 0072$ \\
& $\mathrm{~Pb}(\mathrm{II})$ & $0 \cdot 0004$ & $0 \cdot 0016$ & $-0 \cdot 0065$ \\
& $\mathrm{Cd}(\mathrm{II})$ & $0 \cdot 0019$ & $0 \cdot 0069$ & $-0 \cdot 0038$ \\
5 & $\mathrm{Cu}(\mathrm{II})$ & $-0 \cdot 0021$ & $-0 \cdot 0018$ & $0 \cdot 0032$ \\
& $\mathrm{~Pb}(\mathrm{II})$ & $0 \cdot 0003$ & $0 \cdot 0006$ & $-0 \cdot 0020$ \\
& $\mathrm{Cd}(\mathrm{II})$ & $0 \cdot 0019$ & $0 \cdot 0057$ & $-0 \cdot 0020$ \\
\hline
\end{tabular}

Table 6. Composition of the unknown samples.

Concentration $(\mathrm{mmol} / \mathrm{l})$

Sample number

\begin{tabular}{lcccccccc}
\cline { 2 - 7 } Species & $(1)$ & $(2)$ & $(3)$ & $(4)$ & $(5)$ & $(6)$ & $(7)$ & $(8)$ \\
\hline $\mathrm{Cu}(\mathrm{II})$ & 0.7987 & 0.8662 & $0 \cdot 8711$ & 0.6160 & 0.8352 & 0.7219 & 0.9599 & $0 \cdot 4503$ \\
$\mathrm{~Pb}(\mathrm{II})$ & 1.1458 & 1.0021 & 0.9519 & 0.9419 & $1 \cdot 0351$ & 0.8781 & 0.8224 & 0.7062 \\
$\mathrm{Cd}(\mathrm{II})$ & 1.0008 & 0.8281 & 0.8569 & 0.8723 & 0.9162 & 0.8493 & 0.3176 & $0 \cdot 7637$ \\
\hline
\end{tabular}

Table 7. The concentrations of the unknowns calculated by SPGRFSQ.

\begin{tabular}{|c|c|c|c|c|c|c|c|c|}
\hline \multirow[b]{3}{*}{ Species } & \multicolumn{8}{|c|}{ Concentration $(\mathrm{mmol} / \mathrm{l})$} \\
\hline & \multicolumn{8}{|c|}{ Sample number } \\
\hline & $(1)$ & (2) & (3) & (4) & (5) & (6) & (7) & (8) \\
\hline $\mathrm{Cu}(\mathrm{II})$ & $0 \cdot 8009$ & $0 \cdot 8653$ & $0 \cdot 8718$ & $0 \cdot 6164$ & $0 \cdot 8440$ & $0 \cdot 7204$ & 0.9582 & $0 \cdot 4518$ \\
\hline $\mathrm{Pb}(\mathrm{II})$ & $1 \cdot 1448$ & 1.0033 & 0.9555 & 0.9410 & $1 \cdot 0367$ & 0.8784 & 0.8229 & 0.7048 \\
\hline $\mathrm{Cd}(\mathrm{II})$ & 0.9984 & $0 \cdot 8289$ & $0 \cdot 8553$ & $0 \cdot 8708$ & $0 \cdot 9053$ & $0 \cdot 8509$ & $0 \cdot 3194$ & $0 \cdot 7622$ \\
\hline
\end{tabular}

The values were means of three replicate. 
Table 8. The average recoveries and their relative deviations of the 'unknowns'.

\begin{tabular}{|c|c|c|c|c|c|c|c|c|}
\hline \multirow[b]{3}{*}{ Species } & \multicolumn{8}{|c|}{ Recovery $(\%)$} \\
\hline & \multicolumn{8}{|c|}{ Sample number } \\
\hline & (1) & $(2)$ & (3) & $(4)$ & $(5)$ & (6) & (7) & (8) \\
\hline $\mathrm{Cu}(\mathrm{II})$ & $100 \cdot 28$ & $99 \cdot 90$ & $100 \cdot 08$ & $100 \cdot 07$ & $100 \cdot 06$ & $99 \cdot 79$ & $99 \cdot 82$ & $100 \cdot 32$ \\
\hline $\mathrm{Pb}(\mathrm{II})$ & $99 \cdot 92$ & $100 \cdot 12$ & $100 \cdot 38$ & $99 \cdot 90$ & $100 \cdot 15$ & $100 \cdot 03$ & $100 \cdot 06$ & $99 \cdot 80$ \\
\hline \multirow[t]{3}{*}{$\mathrm{Cd}(\mathrm{II})$} & $99 \cdot 76$ & $100 \cdot 10$ & $99 \cdot 82$ & $99 \cdot 83$ & $100 \cdot 81$ & $100 \cdot 19$ & $100 \cdot 57$ & $99 \cdot 80$ \\
\hline & \multicolumn{8}{|c|}{ Relative deviation $(\%)$} \\
\hline & \multicolumn{8}{|c|}{ Sample number } \\
\hline Species & (1) & (2) & (3) & (4) & (5) & (6) & (7) & (8) \\
\hline $\mathrm{Cd}(\mathrm{II})$ & $0 \cdot 0028$ & $-0 \cdot 0011$ & $0 \cdot 0008$ & $0 \cdot 0007$ & $0 \cdot 0106$ & $-0 \cdot 0021$ & -0.0018 & $0 \cdot 0032$ \\
\hline $\mathrm{Pb}(\mathrm{II})$ & $-0 \cdot 0008$ & $0 \cdot 0012$ & $0 \cdot 0038$ & $0 \cdot 0010$ & -0.0015 & $0 \cdot 0003$ & $0 \cdot 0006$ & -0.0020 \\
\hline $\mathrm{Cd}(\mathrm{II})$ & $-0 \cdot 0024$ & 0.0010 & -0.0018 & -0.0017 & -0.0119 & 0.0019 & 0.0057 & $-0 \cdot 0020$ \\
\hline
\end{tabular}

The values were means of three replicate.

\section{The condition number of the proportionality matrix $P$}

The condition number of the proportionality matrix $P$ $(\operatorname{cond}(P))$ indicates the numerical accuracy that can be lost when the matrix is inverted [8]. The condition number can be used as a measure for selectivity of the multicomponent system. The $\operatorname{cond}(P)$ is usually calculated from the ratio of the largest eigenvalue of $P$ to the smallest eigenvalue; values for eigenvectors 3-7 were 11.9208, $11 \cdot 4773,11 \cdot 4845,11 \cdot 4921$ and $11 \cdot 4961$, respectively. As the number of eigenvectors increased, the value of cond $(P)$ remained almost constant - the selectivity of the spectrophotometric system did not change if the number of eigenvectors increased. This was due to the high degree of spectral overlap of the PAR complexes, giving the system low selectivity.

\section{Conclusion}

Simultaneous determination of $\mathrm{Cu}(\mathrm{II}), \mathrm{Pb}(\mathrm{II})$ and $\mathrm{Cd}(\mathrm{II})$ with PAR by use of the full spectrum techniques in the fourier domain has been shown to be a successful method. The difficulty imposed by overlap of the absorption spectra was overcome by the method. Recoveries of $\mathrm{Cu}(\mathrm{II}), \mathrm{Pb}(\mathrm{II})$ and $\mathrm{Cd}(\mathrm{II})$ were between $98.8 \%$ and $101.1 \%$.

\section{Acknowledgement}

The authors would like to thank the National Natural Science Foundation of China for financial support.

\section{References}

1. Beebe, K. R. and Kowalski, B. R., Analytical Chemistry, 59 (1987), 1007A.

2. Hanland, D. M. and 'Thomas, E. V., Analytical Chemistry, 60 (1988), 1193.

3. Marbach, R. and Heise, H. M., Trends in Analytical Chemistry, 11 (1992), 270.

4. Liang, Y., Kvalheim, O. M. and Manne, R., Chemometrics and Intelligent Laboratory Systems, 18 (1993), 235.

5. Malinowski, E. R., Analytical Chemistry, 49 (1977), 605.

6. Malinowski, E. R., Journal of Chemometrics, 1 (1987), 605.

7. Malinowski, E. R., Journal of Chemometrics, 3 (1988), 49.

8. Jochum, C., Jochum, P. and Kowalski, B. R., Analytical Chemistry, 53 (1982), 85. 


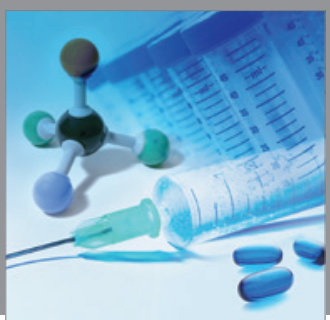

International Journal of

Medicinal Chemistry

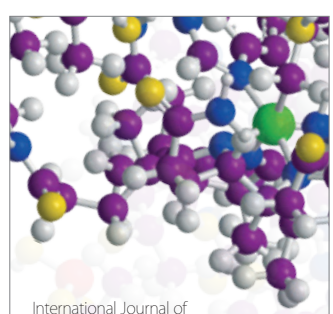

Carbohydrate Chemistry

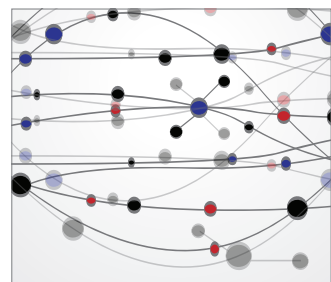

The Scientific World Journal
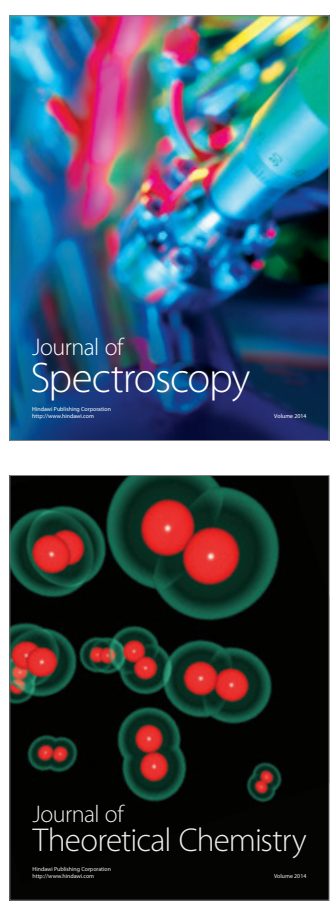
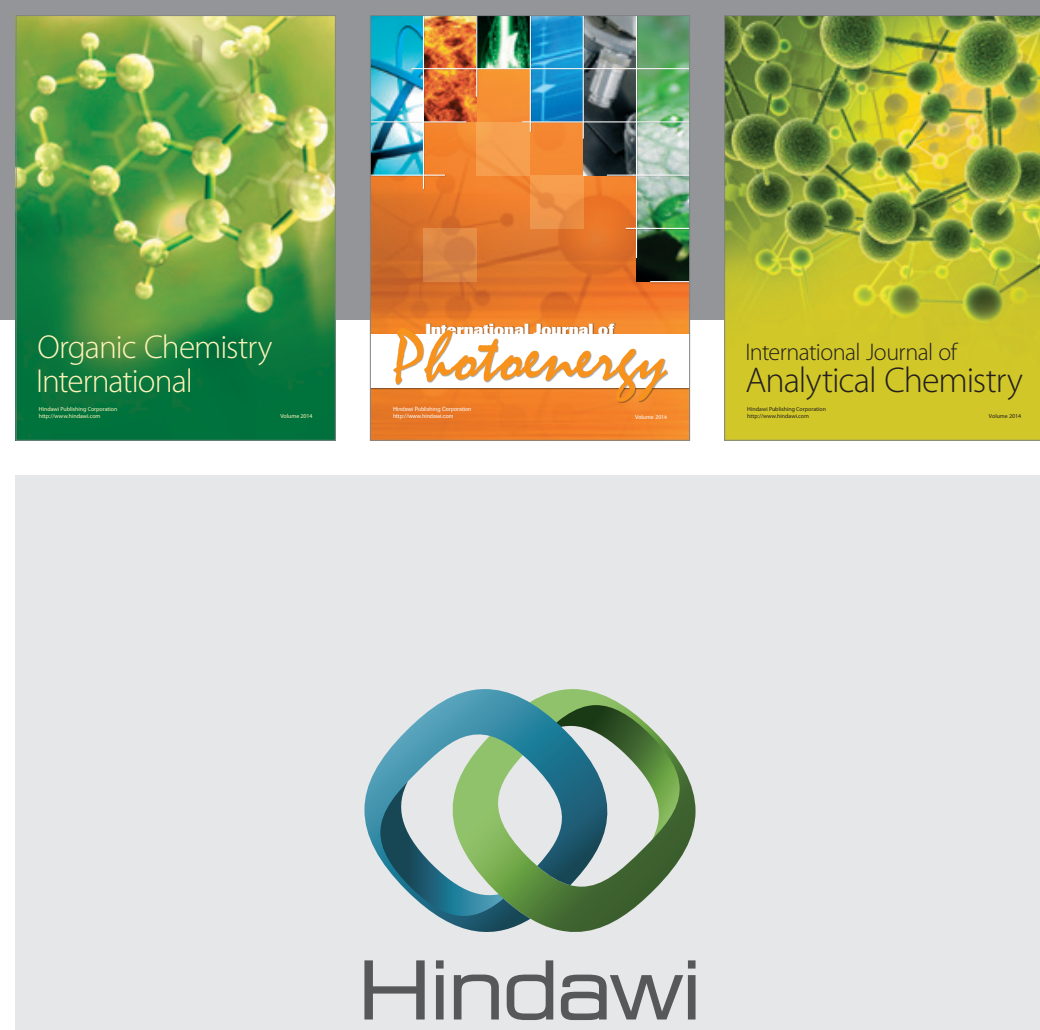

Submit your manuscripts at

http://www.hindawi.com
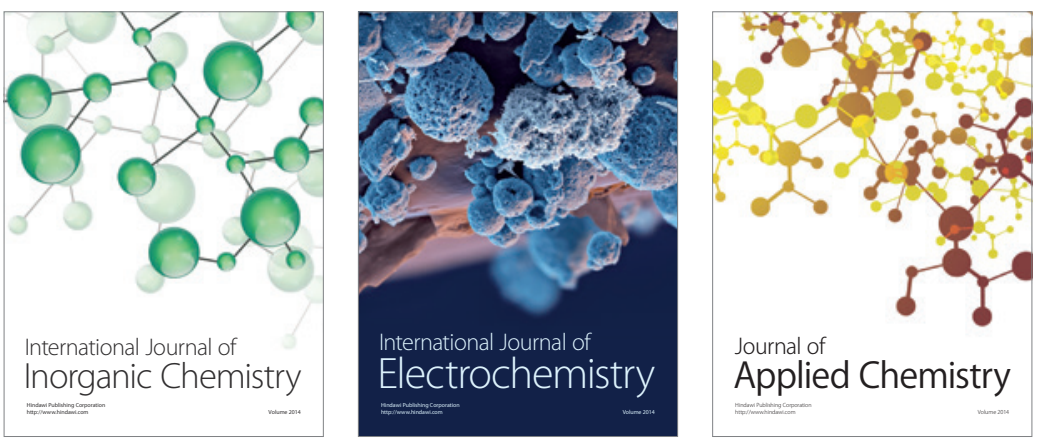

Journal of

Applied Chemistry
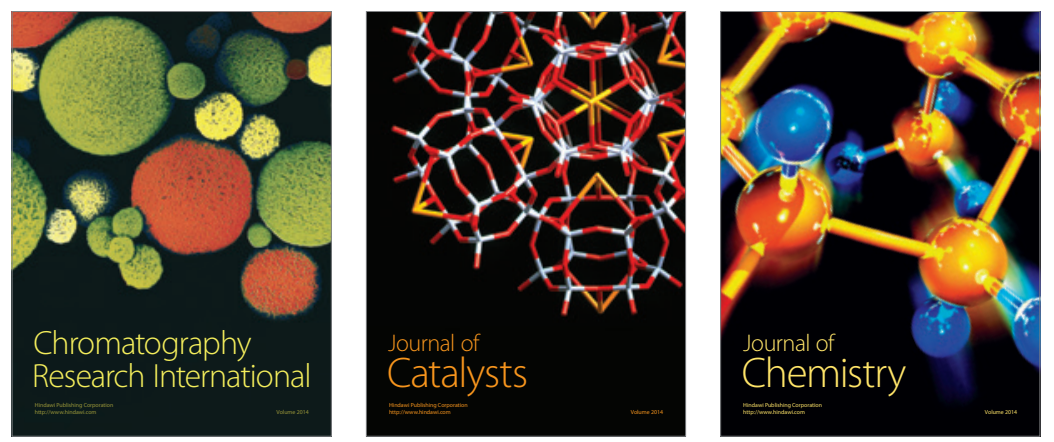
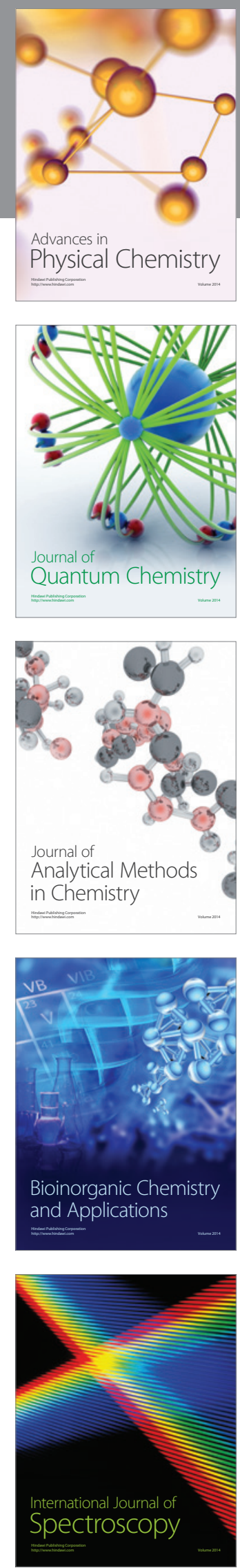